\title{
MIDAS
}

Museus e estudos interdisciplinares

$2 \mid 2013$

Varia

\section{O museu como um instrumento de reflexão social}

The museum as a social reflection tool

\section{Genoveva Oliveira}

\section{(2) OpenEdition}

Journals

Edição electrónica

URL: https://journals.openedition.org/midas/222

DOI: $10.4000 /$ midas.222

ISSN: 2182-9543

\section{Editora:}

Alice Semedo, Paulo Simões Rodrigues, Pedro Casaleiro, Raquel Henriques da Silva, Ana Carvalho

\section{Refêrencia eletrónica}

Genoveva Oliveira, «O museu como um instrumento de reflexão social», MIDAS [Online], 2 | 2013, posto online no dia 01 abril 2013, consultado no dia 21 setembro 2021. URL: http://journals.openedition.org/ midas/222 ; DOI: https://doi.org/10.4000/midas.222

Este documento foi criado de forma automática no dia 21 setembro 2021.

\section{c.) (i) (2)}

Midas is licensed under a Creative Commons Attribution-NonCommercial-ShareAlike 3.0 International License 


\title{
O museu como um instrumento de reflexão social
}

\author{
The museum as a social reflection tool
}

\author{
Genoveva Oliveira
}

\section{Introdução}

1 O estudo realizado para este artigo baseou-se em revisões bibliográficas como um material essencial. A análise e interpretação seguiram os objetivos do estudo proposto. 0 tratamento metodológico dos documentos que se observa neste artigo reporta à mediação em museus e à função social do museu que destacaremos neste trabalho, sublinhando projetos internacionais de diferentes países como um exemplo pertinente a refletir.

Em 1958, teve lugar, no Rio de Janeiro, um Seminário Regional da UNESCO com a finalidade de discutir a função educativa dos museus. Esta reunião foi um marco de suma importância no processo de transformação da instituição museológica na América Latina. Mas as ideias preconizadas no encontro do Chile de $1972^{1}$ vieram trazer uma nova abordagem. Os museus são espaços privilegiados de educação não formal e têm um papel importante na formação de todos, no campo da cultura. A Declaração de Québec de 1984 sistematizou os princípios fundamentais da Nova Museologia. A Declaração de Caracas, resultado do Seminário de Estudos Museológicos, realizado no período de 16 de Janeiro a 6 de Fevereiro de 1992, teve como finalidade fazer um balanço da situação dos museus na América Latina. Desenvolveu uma avaliação crítica deste percurso e reafirmou o museu como uma "forma de comunicação entre os elementos do triângulo - território, património, sociedade -, servindo de instrumento de diálogo, de interação das diferentes forças sociais, económicas e políticas; um instrumento que possa ser útil na sua especificidade e função ao "homem indivíduo" e "homem social", para que este possa enfrentar os desafios que vêm do presente e para o futuro (Horta 1995, 32-35).

3 Para Araújo e Bruno $(1995,19)$, foi o conceito de museu integral que criou uma nova perspetiva de atuação, abrindo as fronteiras tradicionais, trazendo benefícios, mas 
também despertando os museólogos para problemas como a crise de identidade institucional, quando os museus passaram a confundir-se com outras formas de ação cultural.

4 Alexandre Beites $(2011,19)$ considera o museu como um agente de gestão de informação, que deve incentivar um diálogo franco com a sua comunidade, conhecendo a sua opinião e interagindo, visando um processo de construção comum de cultura.

\section{A mudança de paradigma}

5 O museu integral confunde-se com o centro cultural, abrigando outras áreas de conhecimento. O seu acervo deixa o espaço sagrado e vai revelar-se em outros lugares anteriormente jamais pensados, como os centros comerciais, ruas, praças e praias (Lima 2001, 6). Rompe fronteiras, ganha o título de espaço vivo pela nova dinâmica que se propõe e pela própria conceção de vida que essa rotura e vivacidade que proporciona. Como fórum, insere-se numa visão crítica, dialética. E por tudo isso ficamos defronte do museu e interrogamo-nos se ele ainda é museu. Olhando pela ótica dos paradigmas emergentes acreditamos que estamos diante de um novo museu, o museu do nosso tempo. Boaventura Santos $(1988,25)$ refere sobre os novos paradigmas:

No paradigma emergente o conhecimento é total, tem como horizonte a totalidade universal de que fala Wigner ou a totalidade indivisa de que fala Bohm. Mas sendo total, é também local. Constitui-se em redor de temas que em dado momento são adotados por comunidades interpretativas concretas como projetos de vida locais.

6 O autor refere aquilo que Rachel Mason (2001) também sublinha - a necessidade de, num mundo global, continuar a defender o local. Boaventura Santos salienta ainda:

A fragmentação pós-moderna não é disciplinar e sim temática. Os temas são galerias por onde os conhecimentos progridem ao encontro uns dos outros. Ao contrário do que sucede no paradigma atual, o conhecimento avança à medida que o seu objeto se amplia, ampliação que, como a da árvore, procede pela diferenciação e pelo alastramento das raízes em busca de novas e mais variadas interfaces (Santos 1988, 32).

7 O autor estabelece conexões com a teoria da construção "rizomática" de Deleuze e Guattari (2004). A ideia de rizoma leva-nos a interrogar as normas rígidas e os objetivos pré-fixados, propondo novas leituras. O museu sugere novas e diferenciadas relações com a sociedade, atribuindo a si próprio, também, a função de formar o ser humano para o exercício da cidadania, através das mediações entre o acervo exposto e o público.

8 Coelho (1997) refere que os processos de mediação decorrem de naturezas diversas e têm a finalidade de promover a aproximação entre indivíduos, coletividades e obras de cultura e arte. Para o autor

Essa aproximação é feita com o objetivo de facilitar a compreensão da obra, o seu conhecimento sensível e intelectual, com o que se desenvolvem apreciadores ou espetadores, na busca da formação de públicos para a cultura ou de iniciar esses indivíduos e coletividades na prática efetiva de uma determinada atividade cultural (Coelho 1997, 248).

9 O museu, tal como a sociedade, está em constante fase de transmutação tendo obrigatoriamente de acompanhar a evolução dos novos desafios que se colocam diariamente. Novas funções são propostas. Alexandre Beites (2011) sublinha que as políticas dos museus são orientadas para o público, mas o discurso museológico permanece centrado no objeto e não no indivíduo, porque não prevê a interação com ele: 
Este discurso é, na forma e nos conteúdos, pensado por uma equipa multidisciplinar, mas raramente inclui, no processo de planeamento, o futuro "visitante" (estratégia colaborativa); o museu é visto como um local de transmissão de conhecimentos e parte-se do seu postulado científico, para garantir que os seus conteúdos sejam "verdade" $(2011,21)$.

10 O conceito de "museu aberto" passa por enquadrar os museus numa comunidade, que ambiciona uma condição que ainda não existe, mas que futuramente e em função da relação de demonstrações que têm vindo a acontecer, se pode antever a sua concretização. O museu reflexivo é aquele que se auto examina como forma de se construir e de ser capaz de satisfazer o tão aspirado compromisso de construção cultural com a comunidade.

11 Marilyn G. Hood $(1983,51)$ na obra Staying Away: why people choose not to visit museums, sobre estudos de públicos, salienta um conjunto de critérios fundamentais que o museu deve oferecer para que constitua uma atração de diferentes públicos como a capacidade de interação social, fazer algo de útil, o sentimento de agradabilidade, corresponder a desafios e sentir novas experiências, a oportunidade para aprender coisas novas, ter uma atitude ativa. Naturalmente, que um museu que contenha estas características implica deter um profundo conhecimento das suas equipas internas e o conhecimento dos seus públicos. Só é possível desenvolver esta capacidade reflexiva e de comunicação através de uma política de avaliação e auto avaliação (Falk et al 2000; Falk et al 1992; Oliveira 2012).

\section{O museu aberto}

12 Os programas de educação mais eficazes em escolas e museus conseguiram criar associações sustentáveis, a longo prazo e recíprocas com organismos culturais e indústrias. Estas associações são autênticas parcerias, em que todos os atores da parceria reconhecem as contribuições feitas pelos outros (Bamford 2006; Oliveira 2012). Por exemplo, os programas de arte com relevância são construídos à volta da noção de inclusão e uma educação relevante em arte para todos. Isto quer dizer que todas as crianças, independentemente das suas capacidades e competências artísticas, motivação inicial, comportamento, situação económica ou outros atributos, devem ter direito a receberem educação em arte de elevada qualidade, utilizando várias abordagens artísticas e criativas (Robinson 1999, 27-36). Isto é particularmente importante em relação a iniciativas para providenciar a educação a todos e para se procurar uma maior inclusão de uma variedade de grupos marginalizados dentro de uma educação geral. Para encontrarem uma linha de trabalho em termos de qualidade na educação artística, os provedores dessa educação necessitam de garantir que existem programas de arte para todas as crianças. Administrar aulas apenas aos estudantes talentosos ou interessados não pode ser considerado como estando a administrar uma educação para todos (Acaso 2009; Oliveira 2012).

Deve-se providenciar o mesmo acesso à educação artística de alta qualidade a crianças com necessidades especiais e uma oportunidade de se envolverem numa aprendizagem de arte com significado em todas as esferas de esforço criativo (Bahia 2009, 140-141). É importante verificar que o potencial artístico das crianças com necessidades especiais é tão completo como o das outras crianças. Consequentemente, a educação artística deve ser tratada com o mesmo rigor e ambição para todas as crianças. Os programas relevantes em arte têm tendência para florescer em situações onde há margem para uma 
flexibilidade organizacional. Dentro de setores de educação, horários rígidos, compartimentação da aprendizagem e estruturas de avaliação restritivas tendem a limitar a extensão e a qualidade artística e cultural (Bahia 2009, 145). Do mesmo modo, dentro das organizações culturais, os elevados custos, a restrição em limites físicos de uma galeria ou instalação e a falta de flexibilidade administrativa limitam o provável sucesso do envolvimento pleno com o setor da educação. É, portanto, crucial que uma administração que aposte na qualidade da educação envolva abordagens democráticas ao planeamento, à política, à implementação e à avaliação (Robinson 1999, 27-36).

Os museus passaram também a reconhecer que, além das funções de preservar, conservar, expor e pesquisar são instituições ao serviço da sociedade e procuram através das ações educativas tornarem-se elementos vivos dentro da dinâmica cultural das cidades (Sandell 2002; Souza 2002). Porém, ao invés de falarmos de inclusão deveríamos antes defender o sentido da equidade.

15 A inclusão tem sido o grande apanágio da escola portuguesa (e não só) e dos museus nas últimas décadas, mas vemos claramente com frequência que há uma situação diferente relativamente às políticas educativas e à capacidade de as pôr na prática, resultando, por vezes, em profunda exclusão. Como Ramos ó refere (in Niza 2012, 6-7) a cultura escolar arraigou-se de uma política da vida e da identidade pessoal em que a autonomia da escola serve, no essencial, para dar corpo a uma ética da obediência consentida e da padronização social. Niza $(2012,50)$ sublinha que se deve estabelecer uma guerra aberta à ilusão dos grupos homogéneos e exige a necessidade da recapitulação de conteúdos, no sentido de criar a possibilidade de produzir, já a partir da infância os vários processos sociais em que se dá "a construção da cultura toda". Na promoção da sua diferença individual, Niza $(2012,66)$ refere que todos os alunos devem participar na delineação, organização e avaliação da vida da turma e das tarefas escolares. Niza apresenta uma proposta em que aprender dispensa a função de ensinar as lições formais iguais para todos, no sentido de se descobrir na individualização do percurso escolar e no convívio cultural a condição da melhoria das capacidades cognitivas. Ramos ó $(2012,8)$ expõe que Niza questiona a "escola para todos" no sentido que esta, como tem sido colocada na prática, pretende homogeneizar mais do que criar espaços críticos para a individualidade dando a possibilidade dos alunos comparticiparem nas funções de ensino e da escola, de os acompanhar em projetos de trabalho e na resolução de problemas, criando espaços para o relevo do valor cognitivo da controvérsia conceptual através da linguagem, criando novas formas de tutoria entre os alunos, fundamentadas na colaboração e na reciprocidade solidária. Paralelamente, os museus que se apropriaram do "escola para todos" para o adaptar a "museu para todos" sofrem, por vezes, das mesmas dificuldades e constrangimentos.

16 O exemplo dos museus ingleses suscita em nós um profundo interesse pelo esforço que se tem observado nos últimos anos relativamente ao sentido de museu aberto. Estão a vivenciar o que muitos pensam ser a sua maior mudança em cento e cinquenta anos, tendo ultrapassado a vocação tradicional da interpretação das coleções. O Centro de Museus e Galerias realizou em 2002 uma avaliação nacional para o Departamento de Educação do Museu e Galeria de Educação da Fase 1 do Programa. Cartwright Hall em Bradford e o Castel Museum em York. A avaliação dá-nos algumas evidências do impacto desse projeto. As crianças nas escolas foram motivadas pela sua interação com os objetos e cobriram as paredes da sua sala de aula com desenhos, fotografias, poemas e pensamentos. A experiência deu-lhes a inspiração para serem criativos. Os professores 
referiram que lentamente o projeto ajudou as crianças a construir novos significados, a melhorar o vocabulário, ou seja, as crianças desenvolveram aptidões na língua e audição, observação e investigação, pois o acesso ao museu foi promovido de forma significativa (Dodd 2002, 90-92).

Nos museus na Grã-Bretanha, a ênfase está a afastar-se do que era o único interesse em relação ao paradigma da exposição, que conta histórias sobre os objetos. Os curadores dos museus, os gestores e os diretores esforçam-se para satisfazer os requisitos dos novos e múltiplos públicos, na continuidade daquilo que em 1975, o museólogo checo Jan Jelinek preconizava:

A backward glance at museum development shows that museums only fully develop their potential for action when they are actually involved in the major problems of contemporary society. Museums are institutions intended to serve society and only thus can they continue to exist and function $(1975,52-60)$.

18 A maior influência na alteração das condições materiais dos museus ingleses nos últimos vinte anos tem sido a Lotaria Nacional. "Since 1995 the Heritage Lottery Fund (HLF) has invested $£ 1.4 \mathrm{bn}$ in museums and galleries" (Tait 2008, 2). 0 apoio do financiamento da lotaria teve efeitos de arrastamento. 0 impacto local incentivou outros financiadores, autoridades locais, fundações beneficentes, dadores privados, empresários e governo com exceção do Departamento de Cultura, Imprensa e Desporto (DCMS), para contribuir e responder à credibilidade dos planos de negócios, insistência cada vez maior da HLF (Tait 2008, 2).

19 Nos últimos anos da década de 1990, os museus ingleses começaram a ter preocupações sociais. O Museu da Ciência em Londres analisou questões como a SIDA e os efeitos de fumar no átrio do museu. Foram preparadas exposições temporárias que davam resposta aos problemas sociais. A Casa Museu de Carlisle também acrescentou ao seu programa anual esta preocupação social (Tait 2008, 2-3). Esta posição dos museus faz-nos pensar se estamos agora na idade do "pós-museu", expressão já utilizada por vários investigadores, nomeadamente Eilean Hooper-Greenhill (2007) e Marstine (2005). Estarão agora os museus a afirmar-se como uma força potente em termos sociais e de revitalização urbana? No artigo sobre "Conhecimento e Inspiração Democrática" escrito para a "Archives, Museums and Libraries" (Museums, Libraries and Archives Council), em 2006, John Holden e Samuel Jones de Demos referem: "Because of the knowledge they hold and the inspiration they offer, museums, libraries and archives are essential to our social and economy survive" (cit. por Tait 2008, 3). Os objetos que recolhem têm a capacidade de oferecer novas interpretações do mundo.

Uma outra questão que os museus estão cada vez mais a explorar é a migração (salientese os exemplos dos museus ingleses e americanos). No relatório de 2006 da Campanha de Learning supervisionado pelo Home Office, Chris Wood e Hannah Gould, em Inglaterra, refere-se que existem muitas organizações que trabalham com os migrantes. Estas pessoas revelam uma imensa diversidade cultural, espiritual, social, moral e problemas na inclusão na sociedade britânica. Estas organizações acabam por não ter capacidade de atender a esta diversidade por terem de dar prioridade à chegada de novas pessoas com pedidos de asilo, refúgio e de imigração. Hooper Greenhill considera que os museus podem ser uma solução para estas questões (2007, 3-4).

21 Na Dinamarca, iniciativas como "Curador por um dia" no Trapholt, Museu de Arte Moderna e Design em Kolding (Grøn, 2005), "O Laboratório de Estética" no Art Esbjerg Museum e no Arken, Museu de Arte Moderna, perto de Copenhagen, Dinamarca (Illeris 
2008, 7-10) têm contribuído de forma importante para o desenvolvimento de novas e diferentes formas de perceber o encontro educativo entre públicos, obras de arte, exposições, museus, educadores e, em alguns casos, os artistas. Tornou-se importante para a relação entre os museus de arte e os seus públicos que os visitantes tenham experiências de contacto com as obras em exposição (Illeris 2008, 7-10). A fase experimental deste ambiente educacional está relacionada com uma importante tendência que se observa nos museus do Ocidente no sentido de se iniciarem mudanças radicais inserindo práticas mais inclusivas, com base em entendimentos dinâmicos e complexos das relações entre aprendizagem e mudança social (Sandell 2002, 186-190). Mesmo que estes processos pareçam ter começado um pouco mais tarde nos museus de arte do que em outros tipos de museus, (Hooper-Greenhill 2007: 4) na Dinamarca, bem como em outros países escandinavos, muitos museus já começaram a fazer um esforço considerável com iniciativas experimentais dirigidas a grupos sociais que não os públicos tradicionais (Illeris 2008, 7-10).

No caso espanhol destacamos o Programa de Aproximación À Arte Contemporânea do Centro Galego de Arte Contemporânea que dá ênfase aos benefícios que as crianças têm quando visitam centros de arte (museus, exposições, galerias de arte). Trata-se de permitir às crianças de falarem acerca do que veem, com alguém que proporciona a informação e que sirva apenas de moderador da discussão. São as crianças que geram as suas interpretações, que discutem formando assim a sua opinião, fundada no que veem e não no que se lhes conta, assim, ao mesmo tempo que aprendem respeitam o ponto de vista das outras pessoas. Os alunos expressam-se com total liberdade, vão apreendendo uma linguagem própria e aprendem a valorizar outras visões e opiniões (Oliveira 2012, 287).

No exemplo norte-americano distinguimos o Museu de Arte de Seattle que começou por criar uma relação com as escolas em 1996, determinados em demonstrar como o museu e as artes visuais poderiam proporcionar algo importante na vida dos estudantes. A educação artística nas escolas desta zona era quase inexistente, sem linhas gerais de atuação para as várias escolas, dependendo muitas vezes da boa vontade e iniciativa de um professor. Ao criarem um programa sustentado e organizado de forma sistemática que servisse professores e alunos, a equipa do museu permitiu que este se tornasse o mais acessível a todos e com recursos a poderem ser utilizados na sala de aula.

Motivação, desenvolvimento de competências, aspirações crescentes e uma maior acessibilidade são fundamentais para enfrentar o impacto de longo prazo da exclusão. A educação e as ações sociais, juntamente com o acesso à informação e à tomada de decisões, são os passos essenciais iniciais para diluir as barreiras no âmbito físico, intelectual, emocional e até tecnológico. A remoção dessas barreiras é complexa, envolvendo uma abordagem holística do museu. A divulgação do trabalho é apenas uma das componentes de uma aproximação do museu à escola, um dos muitos blocos de construção necessários para que as diversas comunidades começassem a compartilhar a cultura, propriedade das coleções ricas e inspiradoras de museus (Oliveira 2012, 341).

Cuidadosamente planeadas e estruturadas, as sessões interativas de educação estão entre as formas mais poderosas e eficazes de atender às necessidades específicas do público não tradicional, de criar caminhos para a inclusão. As atividades interativas são fundamentais para permitir aos visitantes um olhar interrogador, sem pressupostos de conhecimento prévio. As conversas são estimuladas ao redor das exposições. 0 museu também atua como um espelho, onde as pessoas se podem ver, fazendo conexões entre as suas próprias vidas e as experiências. 

um foco nas necessidades daqueles que são excluídos. Se tomarmos o modelo construtivista de aprendizagem de George Hein e Mary Alexander (1998), a aprendizagem é vista como a construção de um sentido, de um significado baseado na experiência de cada um. Os significados que construímos dependem, portanto, das nossas experiências passadas. Aprender é uma prática ativa, social e contextual, e a motivação é essencial para a aprendizagem. Subjacente a tudo isto, estão as noções da democratização social, igualdade e competências. A interatividade tem que ser um elemento essencial bem como a parte crítica do processo. Mas considerar a interatividade como uma solução rápida para a criação de um museu seria subestimar a complexidade da agenda da inclusão. Acima de tudo, o Construcionismo Social afirma a realidade como criação social. Assim, crenças e realidades múltiplas podem ser igualmente válidas, visto definirem diversas culturas, tempos históricos, experiências de vida. Os museus são, igualmente, criações sociais e as suas definições e práticas têm sido favorecidas por certos grupos em momentos específicos, que comungam e influenciam, na sua disseminação, diferentes conceitos do mundo. Em cada uma das diferentes noções de museu existe sempre uma comunidade de profissionais que reclamam a "verdade", sejam eles colecionadores ou peritos, diretores ou curadores, educadores, visitantes e avaliadores ou gestores e profissionais de marketing (Hein e Alexander 1998, 40). Sendo o significado tomado como relacional, o significado do museu não se limita aos seus objetos ou coleções, exposições e programas educacionais, publicações ou área comercial. Pelo contrário, todos eles produzem significado e, nesse sentido, os visitantes são potenciais catalisadores de construção de significado. Através da organização de exposições e programas baseados em problemáticas, fornecendo múltiplos caminhos que explorem temas como género, classe, sexo, expondo questões de conflito e negociação e confrontando-as a partir de outros pontos de vista é um caminho possível nessa construção do museu plurivocal (Oliveira 2012, 408-411). Os profissionais dos serviços educativos são facilitadores do conhecimento e da interpretação do discurso do museu, promovendo o diálogo com os diversos públicos, criando a possibilidade de diferentes reflexões (a sua e a dos públicos).

A nível local, o sentido de "nós" pode identificar não só uma comunidade, como um museu. Os museus podem ser um foco para a regeneração pós-industrial, por exemplo, mas reabilitar os ambientes urbanos pode variar muito. Por vezes, depende da natureza das comunidades e dos investimentos que as autoridades locais estão dispostas a fazer nos museus de uma cidade (Tait 2008, 12).

Muitos museus estão empenhados em reavaliar as suas coleções e as suas histórias com conotações contemporâneas. A Internet e as tecnologias associadas obrigam a uma evolução mais rápida, submetendo o museu a avançar muito mais rapidamente do que poderia ser há cinco anos atrás. As transformações na sociedade estão a ocorrer em grande velocidade e podem exigir uma resposta rápida dos museus, como tal, a aposta na formação torna-se num desafio. Um novo grupo de pessoas no museu como um urbanista, um professor e um consultor vêm auxiliar a compreensão da essência do objeto e a interpretação da curadoria. Ao mesmo tempo, o setor continua a ter de valorizar muitos curadores tradicionais, que não estão familiarizados com as novas tecnologias, nem com as novas exigências sociais. No entanto, os curadores mais tradicionais necessitam de ser incentivados a criarem novos processos de comunicação (Tait 2008, 14).

MIDAS, 2 | 2013 
Os bloqueios institucionais podem também ser um grande obstáculo. Muitos museus, particularmente os nacionais, são estruturas organizacionais complexas, de longa data $\mathrm{e}$ muitas com estruturas departamentais dentro delas (Tait 2008, 14). A sua complexidade muitas vezes dificulta a necessidade de assumir novas ideias, métodos e interpretações. Porém, as novas tendências incentivam a motivação em olhar para a sua comunidade local como uma inspiração.

\section{Parcerias entre escolas e os museus}

31 O estudo realizado pela UNESCO em 2004, em colaboração com o Conselho para as Artes da Austrália e a Federação Internacional dos Conselhos para as Artes e Organismos da Cultura, uma investigação para se determinar o impacto dos programas de arte na educação das crianças e dos jovens em todo o mundo, prova claramente que o processo de democratização do gesto de criar faz-se de formas muito diversas ou simplesmente não se faz. Apesar dos resultados do estudo indicarem que a arte tem um tributo valioso para a educação integral das crianças, especialmente no que se refere ao seu desempenho académico, bem-estar, atitudes em relação à escola e as perceções da aprendizagem, mas o caráter da educação artística varia consideravelmente de país para país. Além disso, embora a maior parte dos países reconheça o valor da educação artística e cultural, existe uma diferença entre as políticas e a prática (Bamford 2006; Oliveira 2012).

Alguns dos países estudados na investigação da UNESCO, tais como Cuba, Canadá, Países Baixos e Nova Zelândia apresentaram taxas elevadas, tanto na participação como na relevância dada à Educação Artística. Nestes países, os programas são disponibilizados a todos, têm relevo para os vários grupos sociais e em geral têm grande qualidade. Por outro lado, na Bélgica e no Reino Unido, os programas estão geralmente acessíveis, a baixos custos, à maior parte das pessoas, mas apesar disso, as formas de arte experimentadas tendem a atrair uma audiência de elite e nem sempre têm relevância nos diferentes grupos sociais e económicos. Por exemplo, na Austrália e nos EUA, a educação artística é de uma qualidade relevante, mas muitas vezes o acesso a estes programas está limitado a pessoas de um certo estatuto social (Bamford 2006, 43-45). Como referimos anteriormente, a democratização da produção criativa é por vezes inexistente.

Existe uma outra situação, tanto de baixa relevância, como de pouca participação. Nesses países, a Educação Artística e Cultural é insuficientemente apoiada e inacessível. Esta inacessibilidade pode ser provocada por várias razões, como altos custos, falta de conteúdo cultural, isolamento geográfico, exclusão e/ou baixa qualidade. A educação artística e a educação cultural ideal deveriam encorajar elevados níveis de participação e oferecer um programa que fosse por si só de alta qualidade com elevadas taxas de relevância.

Em todos os países da União Europeia, com exceção dos Países Baixos, as decisões relativas à criação dos currículos artísticos e culturais são tomadas unicamente, ou em parte, pelas autoridades educativas centrais. Nos Países Baixos, cabe exclusivamente às escolas e/ou às autoridades organizadoras conceber esses currículos (Educação Artística 2009, 27-30). Na Bélgica (Comunidades francesa e flamenga), Dinamarca, Irlanda, Malta, Países Baixos, Áustria e Noruega, foram criadas organizações para desenvolver a educação artística e cultural através de iniciativas específicas. Na Dinamarca, o Ministério da Cultura criou uma agência chamada "Rede para as Crianças e para a Cultura" com o 
objetivo de coordenar atividades no domínio das crianças, cultura e artes e atuando como conselho consultivo do Ministério da Cultura. Esta rede incentiva as instituições culturais a unirem esforços na conceção de numerosos projetos culturais e ajuda a desenvolver novos métodos (Educação Artística 2009, 27-30). Dado a diversidade das organizações envolvidas, o que se torna claro é que, para se ser capaz de promover programas de educação artística nas escolas, é necessário o apoio de várias instituições, como, por exemplo, os museus.

Em Inglaterra, desde 2003, o Departamento de Cultura, Media e Desporto (DCMS) e o Departamento de Educação e Skills inglês (DFES), passaram para o Departamento de Crianças, Escolas e Famílias (DCSF). Em conjunto, patrocinou uma parceria entre museus regionais e nacionais na Inglaterra, que se destinou a aumentar e a aprofundar as relações entre os museus e as escolas para reforçar relações entre os museus e as comunidades. Uma avaliação do programa foi realizada durante 2006 e 2007. Doze museus nacionais e mais de 50 museus regionais parceiros participaram nesta fase do programa DCMS/DCSF. Desenvolveram-se dezassete projetos em toda a Inglaterra, com diferentes finalidades, âmbito, dimensão, duração, número de parceiros e participantes e alcance geográfico. Um certo número de museus regionais foi parceiro em mais de um projeto. Durante os anos de 2006-07, os museus trabalharam com 1.577 escolas e um total de 71.297 alunos. Um total de 450.357 pessoas assistiu a eventos e a exposições relacionados com os projetos (Hooper Greenhill 2007, 7-8).

Nas parcerias entre o setor da educação e do museu foram observados um aumento de contactos entre estes, especialmente os que envolveram um maior número das sessões, ao longo de um período de tempo. Houve um aumento da participação do número de escolas secundárias e os museus tiveram um papel válido no desenvolvimento do currículo escolar. Foi realizada uma apreciação positiva por parte dos professores sobre a aprendizagem e os métodos utilizados nos museus; estes revelaram o valor positivo dos museus para a sua própria aprendizagem e desenvolvimento profissional; a grande maioria dos professores (96\%) ficaram satisfeitos ou muito satisfeitos com a sua experiência museológica (Hooper Greenhill 2007, 22-26).

A grande maioria dos alunos (mais de 90\%) usufruiu das visitas ao museu; os rapazes mais velhos mostraram mais entusiasmo; os professores continuam a valorizar a qualidade inspiradora do trabalho do museu porque permite que os seus alunos compreendam melhor os objetos; $99 \%$ dos professores pensam que os alunos beneficiaram da experiência museológica; $97 \%$ dos professores pensam que os alunos são suscetíveis de serem inspirados para saber mais; $94 \%$ dos professores pensam que os alunos terão adquirido conhecimento relacionado com factos; $82 \%$ dos professores consideraram que a experiência no museu é suscetível de influenciar a classe docente; $94 \%$ dos professores pensam que os alunos são suscetíveis de desenvolverem competências de pensar/refletir e $89 \%$ dos professores consideram que os alunos desenvolvem capacidades comunicativas (Hooper Greenhill 2007, 31-37).

38 O trabalho comunitário é relativamente novo, em muitos dos museus que participaram neste estudo. Alguns museus estavam a usar novas formas de envolvimento com as comunidades, mas alguns não conseguiram compreender o que era necessário para aumentar essa participação. Porém, a maioria dos líderes dos grupos estava satisfeita com as suas experiências. Todos os resultados da aprendizagem foram considerados muito positivos. Nem todos os museus pareciam prontos para o trabalho, necessitando de 
mudanças culturais internas para inserir a aprendizagem baseada no conceito de museu da cultura na comunidade (Tait 2008, 15).

Das provas fornecidas pelos professores, alunos, comunidade de trabalhadores e participantes envolvidos no estudo, verificou-se que, nesta abordagem, a aprendizagem é muito valorizada pelos participantes, que as consideram agradáveis, experimentando muitas vezes um sentido de realização nas suas experiências. Há uma melhoria dos resultados nos jovens desfavorecidos permitindo-lhes produzir tal como os seus pares. Um outro foco das atividades zelou também por jovens com necessidades educativas especiais, reduzindo o número de pessoas sem apoio na educação, emprego ou formação. Quando os museus estavam a trabalhar com as pessoas mais vulneráveis, especialmente jovens, tiveram a prova do poder das experiências que os museus podem motivar e inspirar para a aprendizagem. Aos jovens com uma vida caótica, por vezes uma instabilidade transitória, foi dado espaço para refletir e pensar no seu próprio auto desenvolvimento. A longo prazo, foram criadas as oportunidades para a estabilidade.

Para muitos dos professores, no presente estudo, a visita ao museu foi sentida como um catalisador para a aprendizagem, porque foi memorável e inspiradora. As visitas foram integradas no currículo, os alunos foram capazes de aproveitar as suas experiências com as coleções do museu, muitas vezes desconhecidas, para os seus trabalhos escolares, proporcionando ambientes de verdadeira "matéria-prima" para a imaginação, como, por exemplo, em escrita criativa. No entanto, há mais trabalho a ser feito, nomeadamente comunicar o valor dos museus aos professores, especialmente aos professores do ensino secundário, para o currículo e para a forma como a aprendizagem oferecida pelos museus pode facilitar uma mais ampla abordagem à aprendizagem adotada pelo reformas do currículo (Tait 2008, 15).

41 Muitos dos projetos que participaram no estudo vieram promover ativamente o desenvolvimento profissional dos professores. $78 \%$ dos professores envolvidos neste estudo consideraram que o museu tinha ajudado no seu desenvolvimento profissional e que a experiência museológica tinha auxiliado a aumentar os seus conhecimentos e a compreensão, aumentando a sua confiança em relação aos temas, através desses materiais, tendo sido expostos a novos métodos de ensino, novas ideias que poderiam ser levadas para a sala de aula e a novas competências que poderiam utilizar no ensino (Hooper Greenhill 2007, 31-37). Um pequeno número de professores entendeu que a experiência museológica os ajudou a ver os seus alunos de forma diferente, tornando-os mais conscientes da importância do desenvolvimento do aluno como indivíduo. Estes resultados são positivos em função da mudança do currículo, sugerindo que os professores estão a encontrar no museu uma valiosa fonte de aprendizagem e inspiração, não só para os seus próprios alunos, mas também para si próprios (Hooper Greenhill 2007, 31-37).

\section{Conclusão}

42 A análise de Bamford (2007) foi fundamental para refletirmos sobre a importância dos programas de elevada qualidade que disponibilizam uma diversidade de experiências de aprendizagem variada e atrativa com o objetivo de encorajar a criança a revelar as suas ideias. Sabe-se que todas as crianças possuem um potencial para a expressão artística e, portanto, a ênfase é posta na produção e no desempenho. Os programas de qualidade fazem conexões artísticas com o ambiente local. Essa ligação aumenta a relevância do 
projeto. Através da utilização de artistas locais e de obras de arte, de museus locais e outras instituições culturais, os professores esperam que as crianças façam as suas ligações pessoais com a arte. Outros programas associados podem exercer uma forte influência nas mudanças sociais e podem ser utilizados para incrementarem a autoestima das crianças e tratarem de questões de justiça e de igualdade social dentro da comunidade.

Analogamente, consideramos que o testemunho de Siza (2012) é revelador da extensíssima necessidade de analisarmos verdadeiramente o conceito de inclusão e de equidade, da forma como a escola tem vinculado os princípios de uniformidade, homogeneização e normalização dos comportamentos, que na prática se revelam através de um modelo organizacional profundamente seletivo e discriminatório e que esse modelo é por vezes repetido pelas instituições culturais como os museus. Tal como Niza, defendemos uma cultura por via da diferença que permita um lugar para a individualidade. Quando chegarmos a esse momento de ensinamento e de crescimento como seres humanos e profissionais, deixaremos de continuar incessantemente a defender o "estandarte" da inclusão, porque esta será uma prática já incorporada.

Relativamente ao exemplo dos museus, a avaliação mostra como a investigação nestas instituições pode contribuir para um eficaz número de alterações na coesão comunitária e na inclusão social, na revisão do currículo, na implementação de Excelência e Prazer nas escolas, no desenvolvimento profissional de professores, no desenvolvimento das escolas e do currículo (Hooper Greenhill 2007, 44). Houve evidências no estudo inglês mencionado que os museus não estão apenas a tentar resolver os problemas básicos, físicos e materiais das barreiras culturais, mas podem, muitas vezes, responder às complexas necessidades de sub-representação de certos públicos. Naturalmente, o caso inglês conta com o apoio Lotaria Nacional, tendo surtido uma grande influência na alteração das condições materiais dos museus ingleses nos últimos vinte anos. Houve um desejo genuíno entre os museus envolvidos para analisar questões de inclusão social através do desenvolvimento de estratégias para trabalhar com pessoas e grupos vulneráveis, em risco de exclusão social, para chegar a novos públicos ou fazer a diferença na vida das pessoas, através de metodologias como melhorar a sua aprendizagem, desenvolver capacidades ou facilitar a sua participação numa sociedade mais ampla. Os projetos dos museus foram avaliados pelos participantes e trabalhadores do ensino/museu com o objetivo de desenvolver competências sociais, de comunicação e para desenvolver a confiança, por exemplo, no uso de espaços públicos e facilitar a integração na comunidade (Hooper-Greenhill 2007, 44).

Fazer bem em educação é entendido como o mais eficaz meio de combate à pobreza e desinteresse. Coloca-se a tónica na necessidade de assegurar que todos os jovens estão ativos, capazes de atingir o seu pleno potencial, independentemente da sua origem ou circunstâncias. $O$ estudo inglês e os outros exemplos internacionais mencionados reforça o que os estudos anteriores ilustraram que os museus são capazes de contribuir para este objetivo. Os museus fornecem uma elevada qualidade nas abordagens da aprendizagem focalizada. Muitas delas implicam uma cuidadosa investigação sobre as abordagens e atividades para servir os interesses e objetivos dos alunos e das comunidades participantes. A aprendizagem é facilitada pela dinâmica e nas formas imaginativas.

Os museus estão bem posicionados para apoiar o aumento da ênfase nas políticas educacionais, para responder às necessidades individuais dos alunos e desenvolver um 
currículo que motive e envolva todos os alunos, incentive a sua curiosidade e o prazer em aprender e que os ajude a ter êxito (Hooper-Greenhill 2007).

Para as escolas inglesas, a influência do conceito de Excelência e Prazer encorajou o progresso do projeto e permitiu desenvolver um currículo rico e emocionante, que ensina de forma eficaz e faz uso da criação de fortes relações entre os indivíduos, para que o conhecimento dos alunos e as suas competências possam ser utilizados em todo o processo de aprendizagem.

O museu de comunicação ou "museu aberto" é aquele que espelha uma constante auto análise, a partir do seu próprio núcleo interior, num processo de construção permanente, mas que tem igualmente a capacidade de se relacionar com outras instituições e de reavaliar o seu processo, em debate com a comunidade. A experiência inglesa relatada demonstra este desafio perante a relação com diferentes comunidades mostrando uma nova dinâmica museológica, mas também uma participação ativa dos públicos, tendo revelado ser positiva pelas diferentes aprendizagens e resultados obtidos.

\section{BIBLIOGRAFIA}

Acaso, Maria. 2009. La educación artística no son manualidades, Nuevas praticas en la enseñanza de las artes y la cultura visual. Madrid: Catarata.

Araújo, Marcelo Mattos e Cristina Bruno, orgs. 1995. A memória do pensamento museológico brasileiro: documentos e depoimentos. Comité Brasileiro do ICOM.

Bahia, Sara. 2009. Constrangimentos à expressão artística. Invisibilidades, Revista Ibero-Americana de Pesquisa em Educação, Cultura e Artes, 0.

Bamford, A. 2006. The Wow Factor: Global Research Compendium on the Impact of the Arts in Education. Berlim: Waxmann Verlag.

Beites, Alexandre. 2011. O Museu Aberto e Comunicativo, fundamentação e proposta para estudos de públicos à luz de um enfoque info-comunicacional. Tese de Mestrado, Universidade do Porto.

Coelho, M.C.P. 1997. Da origem dos Museus, do seu conteúdo, arquitetura e livre acesso. Brotéria. Cultura e Informação.

Deleuze, G. e F. Guattari. 2000. Rizoma, Introducción. Valencia: Pre-Textos.

Dodd, Jocelyn e Richard Sandell. 2001. Including Museums: Perspectives on Museums, Galleries and Social Inclusion. Leicester: Research Centre for Museums and Galleries.

Dodd, Jocelyn. 2002. Interactive Learning in Museums of Art and Design_Interactivity and Social Inclusion. Research Centre for Museums and Galleries, University of Leicester.

Educação artística e cultural nas escolas da Europa. 2009. Agência de Educação, Comissão Europeia.

Falk, John Howard e Lynn Diane Dierking. 1992. The Museum Experience. Washington: Whalesback Books. 
Falk, John Howard e Lynn Diane Dierking. 2000. Learning from museums: Visitor experiences and the making of meaning. Walnut Creek: AltaMira Press.

Grøn, Karen. 2005. When the Visitor becomes Curator for a day, Artikelbasen, Trapholt. Museum of Modern Art, Applied Art, Design and Furniture Design.

Hein, George e Mary Alexander. 1998. Museums, Places of Learning. American Association of Museums.

Hood, M.G. 1983. After 70 years of audience research, what have we learned? Who comes to museums, who does not, and why? Thompson, D., Bitgood, S., Benefeld, A., Shettel, H. and Williams, R. et al., ed. Visitor Studies, Theory, Research and Practice, 5 :77-87, Jacksonville, FL. Visitor Studies Association.

Hooper-Greenhill, Eilean et al. 2007. Inspiration, Identity, Learning: The Value of Museums Second Study: An evaluation of the DCMS/DCSF National/Regional Museum Partnership Programme in 2006-2007. RCMG, University of Leicester.

Hooper-Greenhill, Eilean. 2007. Museums and Education, Purpose, Pedagogy, Performance. London: Routledge.

Horta, Maria de Lourdes Parreiras. 1995. Semiótica e Museu. Cadernos de Ensaios: estudos de museologia. 2. Rio de Janeiro. IPHAN.

Illeris, H. 2008. The Art Laboratory at Arken. Copenhagen. Arken, Museum of Modern.

Jelinek, Jan. 1975. “The Modern, living museum”. Museum International, XXVII(2).

Lima, Janice Shirley Souza. 2001. O Museu do nosso tempo. Revista Traços, Centro de Ciências Exatas e Tecnologia da Unama, 4(8).

Marstine, Janet, ed. 2005. New Museum Theory and Practice: An Introduction. Malden e Oxford: WileyBlackwell.

Mason, Rachel. 2001. Working Topic Training of Teachers/ Professors. UNESCO Regional Meeting of Experts on Arts Education at school level in Latin America and the Caribbean in Brazil.

Oliveira, Genoveva. 2012. Museus e Escolas: os serviços educativos dos museus de arte moderna e contemporânea, um novo modo de comunicação e formação. Tese de doutoramento, Universidade de Évora.

Padró, Carla. 2003. La museología crítica como una forma de reflexionar sobre los museos como zonas de conflicto e intercambio in Jesús-Pedro Lorente et al. orgs., Museologia Crítica y Arte Contemporaneo, Zaragoza: Prensas Universitárias de Zaragoza.

Primo, Judite. 1999. Museologia e Património: Documentos Fundamentais - Organização e Apresentação. Cadernos de Sociomuseologia, 15.

Ramos Ó, Jorge. 2012. Conhecer e enfrentar o intolerável da escola com Sérgio Niza. Niza, Jorge. Escritos de Sérgio Niza: Escritos sobre educação. Tinta da China.

Robinson, K. 1999. Culture, Creativity and the Young: Developing Public Policy. Cultural Policies Research and Development. Estrasburgo: Conselho da Europa.

Sandell, Richard. 2002. Museums, Society and Inequality. London: Routledge.

Santos, Boaventura de Sousa. 1988. O Social e o Político na Transição Pós-Moderna, in Miranda, José Bragança de, Rodrigues, Adriano Duarte, orgs., Revista Comunicação e Linguagens, 6/7. Moderno/Pós-moderno, Lisboa, Departamento de Comunicação Social da Universidade Nova de Lisboa. 
Tait, Simon. 2008. Can museums be a potent force in social and urban regeneration? Joseph Rowentree Foundation. www.jrf.org.uk (consultado em março 12, 2012).

\section{NOTAS}

1. Mesa-Redonda de Santiago do Chile, ICOM, 1972. Os Princípios de Base do Museu Integral "consideraram que a tomada de consciência pelos museus, da situação atual, e das diferentes soluções que se podem vislumbrar para melhorá-la, é uma condição essencial para sua integração na vida da sociedade. Desta maneira, consideraram que os museus podem e devem desempenhar um papel decisivo na educação da comunidade" (Primo 1999, 95- 104).

\section{RESUMOS}

Cada vez mais, o museu reafirma-se na contemporaneidade como um museu aberto, de comunicação que atende à função do homem como indivíduo e do homem como um ser social. Os museus revelam o desejo de procurar novos públicos ou procuram realizar a diferença na vida das pessoas. O progresso dos últimos anos tornou possível conhecer as características de diferentes públicos, o que pode facilitar a aprendizagem e o conhecimento de uma variedade de competências cognitivas, como o pensamento divergente, a análise crítica, uma melhor compreensão do passado, a complexidade do mundo e as questões ambientais. Através de diferentes exemplos de projetos em museus, pretendemos neste artigo refletir sobre a problemática social da mediação nos museus.

Increasingly, the museum re-asserts itself as an open, communicative museum which serves man as an individual and man as a social being. Museums show a desire to reach out to new audiences, or to make a difference in people's lives. Learning in museums is a by-product of the free interaction of leisure-oriented visitors with exhibitions and their surroundings. Progress in recent years has made it possible to design features in public environments which can facilitate the voluntary learning of a variety of cognitive skills, such as divergent thinking, critical analysis, better understanding of the past, the complexity of the natural world and critical environmental issues. Through different examples of museum projects, we intend, in this article, to reflect on the issue of social mediation in museums.

\section{ÍNDICE}

Keywords: mediation, equity, evaluation, museums and education

Palavras-chave: mediação, equidade, avaliação, museus e educação 


\section{AUTOR}

\section{GENOVEVA OLIVEIRA}

Licenciada em História e Ciências Sociais, mestre em História Regional e Local (História de Arte/ Museologia), Doutoramento em História de Arte/Museologia, é investigadora do Centro de Investigação de História de Arte e Investigação Artística (CHAIA) da Universidade de Évora, colaborando nas áreas de investigação da museologia e educação artística. Tem experiência do ensino secundário e universitário, formação em educação artística e museologia, participa em diversos projetos de investigação, tendo apresentado já diversos artigos científicos e diversas comunicações em Portugal e no estrangeiro. genovevaoliveira@gmail.com 